\title{
Hematuria and Hematospermia Associated with the Use of Finasteride for the Treatment of Androgenic Alopecia: A Case Report
}

\author{
Abdel-Motaal M. Fouda ${ }^{1} \cdot$ Anees M. Bazeed $^{2}$
}

Published online: 31 October 2017

(c) The Author(s) 2017. This article is an open access publication

\begin{abstract}
In this report we address an unusual adverse effect of finasteride (Propecia $1 \mathrm{mg}$ tablets) that was associated with painless hematuria and hematospermia in a 38 -year-old healthy male during treatment of androgenic alopecia at a dose of $1 \mathrm{mg} /$ day. It was found that the bleeding was linked to finasteride use as it occurred 2-3 days after use and stopped upon discontinuation of the drug. The patient was subjected to urological examination, laboratory investigations, and radiological imaging to identify the probable cause of bleeding. It appeared the bleeding was most probably of prostatic origin in the absence of obvious underlying pathology. The frequency of such unusual bleeding remains to be investigated in large clinical trials to address its exact mechanism, predisposing factors, clinical significance, and potential long-term consequences.
\end{abstract}

Abdel-Motaal M. Fouda

foudaamm@mans.edu.eg

Anees M. Bazeed

bazeed.a.m@gmail.com

1 Faculty of Medicine, Mansoura University, Mansoura 35516, Egypt

2 New Mansoura General Hospital, Mansoura, Egypt

\section{Key Points}

We provide an unprecedented report of hematuria and hematospermia caused by finasteride $1 \mathrm{mg}$ /day.

The mechanism and predisposing factors of such bleeding remain to be clarified.

Clinicians should pay attention to this adverse effect in order to properly identify its frequency and severity.

\section{Introduction}

Finasteride, a $5 \alpha$-reductase inhibitor, was approved in 1992 for the treatment of benign prostatic hyperplasia (BPH) at $5 \mathrm{mg} /$ day and in 1997 for androgenic alopecia (AGA) at $1 \mathrm{mg} /$ day [1]. Commonly reported adverse effects of finasteride include impotence and decreased libido [2, 3]. According to the most available data from clinical trials and up-to-date information from US FDA documents, there are no reports on hematuria and/or hematospermia as adverse effects linked directly to the use of finasteride for the treatment of either BPH or AGA [3, 4]. Contrary to this, finasteride proved to be effective for the treatment of prostatic bleeding owing to its ability to reduce microvessel density in the suburethral prostatic tissue via inhibition of angiogenic growth factors such as vascular endothelial growth factor (VEGF) [5]. In this report, we address an unusual adverse effect of finasteride (Propecia tablets) in a 38-year-old male, which caused terminal and painless 
hematuria and hematospermia in the specified dose when used for the treatment of AGA.

\section{Case Report}

A 38-year-old male presented to the urology clinic complaining of voiding painless drops of bloody urine, seen after voiding clear urine. This condition is also associated with bloody seminal ejaculates seen near the end of normal ejaculation. On history taking, the patient mentioned that he had been taking finasteride $1 \mathrm{mg} /$ day (Propecia tablets) for 2 weeks for the prevention of progressive scalp hair loss. The patient also mentioned that he had had a similar attack of this condition 3 months previously when he was receiving Propecia $1 \mathrm{mg} /$ day for the same indication. However, when he noticed this problem, his doctor advised him to stop taking Propecia, upon which the condition was completely resolved without further treatment and without performing further tests to investigate the cause of the hemorrhage. Two weeks later, as the patient was worried about his progressive scalp hair loss, he resumed taking Propecia $1 \mathrm{mg} /$ day as a self-prescription, but is now complaining of recurring hematuria and hematospermia.

The patient mentioned that he has a stable marital life and had not suffered any prior sexual or urinary problems. In addition, he had not performed heavy physical exercise or received any medication concomitant with this condition. On examination, blood pressure was normal and there was no loin pain or tenderness. External genitalia were normal and there were no palpable masses or tenderness in the scrotum, perineum, and penile shaft. Digital rectal examination revealed normal size and consistency of the prostate, with no tenderness or craggy elements. Prostatic massage caused faintly blood-tinged, slimy urethral mucous.

Biochemical analysis showed hemoglobin $14.5 \mathrm{~g} / \mathrm{dL}$, white blood cell count $7.4 \times 10^{9} / \mathrm{L}$, platelet count $305 \times 10^{9} / \mathrm{L}$, international normalized ratio 1.12 , and prostate-specific antigen $2.6 \mathrm{ng} / \mathrm{mL}$. There was no evidence of sexually transmitted disease, and no urinary infection was detected with urine culture. Pelvic X-ray and transrectal ultrasonography revealed free genitourinary organs and average-sized prostate, with no suspicious calculus shadows.

The patient was advised to stop finasteride, and within $48 \mathrm{~h}$ after stopping the drug the bleeding ceased completely without any further treatment; no bleeding was seen for 3 weeks until finasteride was again resumed as a rechallenge test, which resulted in recurrence of bleeding after 3 days. The drug was finally stopped and no bleeding has seen for 1 year, with careful follow-up of genitourinary functions and laboratory investigations.

\section{Discussion}

Hematuria and hematospermia are unreported adverse effects of finasteride. According to the most recent clinical trials and the latest FDA information, there are no reports of the occurrence of hematuria and/or hematospermia complicating the use of finasteride for either BPH or AGA [4]. However, a 2015 meta-analysis study concluded that the existing clinical trials on the treatment of AGA with finasteride are of poor quality, provide very limited data on toxicity, and tend to be methodically biased toward underdetection of adverse events. Moreover, the trials submitted to the US FDA for approval for hair loss excluded most men who would typically be recommended finasteride for the treatment of AGA [6, 7].

The present article provides the first case report that finasteride $1 \mathrm{mg} /$ day, the dose used for the treatment of male pattern baldness, can itself be a cause of hematuria and hematospermia. According to the adverse drug reaction (ADR) probability criteria, this specific ADR was scored 9 on the ADR probability scale [8], and could thus be considered a 'definite' reaction as it followed a reasonable temporal sequence after finasteride, was confirmed by withdrawal and exposure to the drug, and could not be reasonably explained by the known characteristics of the patient's clinical state. We have therefore confirmed the reason and effect relationship between this type of ADR and finasteride.

The pattern of such bleeding suggests a prostatic site of origin, but how finasteride causes such prostatic bleeding is not understood. Prostatic bleeding is usually caused by the friable microvascular network of the prostate, the vessels of which are under the control of angiogenic growth factors, such as VEGF, which in turn are induced by androgen hormones [9]. While it could be well understood that finasteride reduces prostatic microvessel density via inhibition of androgen-induced angiogenic growth factors [5], we can postulate that, at this point, the sudden lowering of androgen levels by finasteride might also result in disruption of the friable androgen-sensitive microvascular network in prostatic tissue, although the exact cause of bleeding remains to be confirmed. Both physical examination and investigations performed for this case provided no convenient explanation for the possible underlying cause of bleeding. It may have been necessary to obtain a prostatic biopsy for examination but this was not feasible in light of the patient's refusal.

\section{Conclusion}

Finasteride use was associated with hematuria and hematospermia in a 38-year-old healthy male during treatment of AGA. The bleeding appears to be of prostatic 
origin and directly linked to finasteride use. This unusual adverse effect remains to be investigated on the mechanistic level, and to be evaluated for its predisposing factors, clinical significance, and potential long-term outcome.

\section{Compliance with Ethical Standards}

Funding No sources of funding were used to assist in the preparation of this study.

Financial disclosure The authors have no financial relationships to disclose relevant to this article.

Conflicts of interest Abdel-Motaal Fouda and Anees Bazeed declare that they have no conflicts of interest relevant to this case report.

Informed consent Written informed consent was obtained from the patient for the publication of this case report, and a copy may be requested for review from the corresponding author.

\section{IRB Approval Code R/17.06.103.}

Open Access This article is distributed under the terms of the Creative Commons Attribution-NonCommercial 4.0 International License (http://creativecommons.org/licenses/by-nc/4.0/), which permits any noncommercial use, distribution, and reproduction in any medium, provided you give appropriate credit to the original author(s) and the source, provide a link to the Creative Commons license, and indicate if changes were made.

\section{References}

1. Marks LS. 5 $\alpha$-Reductase: history and clinical importance. Rev Urol. 2004;6(Suppl 9):S11-21.

2. Mella JM, Perret MC, Manzotti M, Catalano HN, Guyatt G. Efficacy and safety of finasteride therapy for androgenetic alopecia: a systematic review. Arch Dermatol. 2010;146(10):1141-50.

3. Liu L, Zhao S, Li F, et al. Effect of $5 \alpha$-reductase inhibitors on sexual function: a meta-analysis and systematic review of randomized controlled trials. J Sex Med. 2016;13(9):1297-310.

4. eHealthMe. Finasteride and hematospermia-from FDA reports. http://www.ehealthme.com/ds/finasteride/hematospermia/.

5. Pareek G, Shevchuk M, Armenakas NA, et al. The effect of finasteride on the expression of vascular endothelial growth factor and microvessel density: a possible mechanism for decreased prostatic bleeding in treated patients. J Urol. 2003;169:20-3.

6. Belknap SM, Aslam I, Kiguradze T, et al. Adverse event reporting in clinical trials of finasteride for androgenic alopecia: a metaanalysis. JAMA Dermatol. 2015;151(6):600-6.

7. Moore TJ. Finasteride and the uncertainties of establishing harms. JAMA Dermatol. 2015;151(6):585-6.

8. Naranjo CA, Busto U, Sellers EM, et al. A method for estimating the probability of adverse drug reactions. Clin Pharmacol Ther. 1981;30(2):239-45.

9. Schatzl G, Madersbacher S, Haitel A, et al. Associations of serum testosterone with microvessel density, androgen receptor density and androgen receptor gene polymorphism in prostate cancer. J Urol. 2003;169(4):1312-5. 